Mafdy Basta MD, Paul Sloan MD

\title{
Epidural hematoma fol- lowing epidural catheter placement in a patient with chronic renal failure
}

Purpose: We report a case of epidural hematoma in a surgical patient with chronic renal failure who received an epidural catheter for postoperative analgesia. Symptoms of epidural hematoma occurred about $60 \mathrm{hr}$ after epidural catheter placement.

Clinical features: A 58-yr-old woman with a history of chronic renal failure was admitted for elective abdominal cancer surgery. Preoperative laboratory values revealed anemia, hematocrit $26 \%$, and normal platelet, PT and PTT values. General anesthesia was administered for surgery, along with epidural catheter placement for postoperative analgesia. Following uneventful surgery, the patient completed an uneventful postoperative course for $48 \mathrm{hr}$. Then, the onset of severe low back pain, accompanied by motor and sensory deficits in the lower extremities, alerted the anesthesia team to the development of an epidural hematoma extending from $T_{12}$ to $L_{2}$ with spinal cord compression. Emergency decompressive laminectomy resulted in recovery of moderate neurologic function.

Conclusions: We report the first case of epidural hematoma formation in a surgical patient with chronic renal failure (CRF) and epidural postoperative analgesia. The only risk factor for the development of epidural hematoma was a history of CRF. High-risk patients should be monitored closely for early signs of cord compression such as severe back pain, motor or sensory deficits. An opioid or opioid/local anesthetic epidural solution, rather than local anesthetic infusion alone, may allow continuous monitoring of neurological function and be a prudent choice in high-risk patients. If spinal hematoma is suspected, immediate MRI or CT scan should be done and decompressive laminectomy performed without delay.

Objectif : Citer le cas d'un hématome épidural, dont les premiers symptômes sont apparus $60 \mathrm{~h}$ environ après la mise en place d'un cathéter épidural pour une analgésie postopératoire chez une patiente atteinte d'insuffisance rénale chronique.

Eléments cliniques : Une femme de 58 ans, avec antécédents d'insuffisance rénale chronique a subi une chirurgie élective pour un cancer abdominal. Les résultats de laboratoire ont révélé de l'anémie, une hématocrite à $26 \%$, des valeurs normales de plaquettes. TP et TTP. L'anesthésie générale et la mise en place d'un cathéter épidural, pour assurer l'analgésie postopératoire, ont été réalisés. La chirurgie et les 48 premières heures postopératoires se sont bien déroulées. Puis, la survenue d'intenses douleurs lombaires et de déficit moteur et sensitif aux membres inférieurs, a signalé le développement d'un hématome épidural, s'étendant de $T_{12}$ à $L_{21}$ et d'une compression de la moelle épinière. Une laminectomie de décompression d'urgence a permis le retour d'une fonction neurologique modérée.

Conclusion : Nous rapportons le premier cas de formation d'hématome épidural après une analgésie épidurale postopératoire chez une patiente de chirurgie avec antécédents d'insuffisance rénale chronique (IRC), l'unique facteur de risque de développement d'un hématome épidural. Chez des patients à haut risque, un opiacé ou une solution épidurale d'opiacé et d'anesthésique local, plutôt qu'une perfusion d'anesthésique local seulement, constitue un choix prudent et permet une surveillance continue de la fonction neurologique. On peut déceler ainsi les premiers signes de compression de la moelle, comme une douleur lombaire intense et des déficits moteurs ou sensitifs. Si un hématome spinal est soupçonné, on devrait procéder sans tarder à un examen d'IRM ou de tomodensitométrie et à une laminectomie de décompression immédiate.

From the Department of Anesthesiology, University of Kentucky, Lexington, Kentucky, USA.

Address correspondence to: Paul A. Sloan MD, Department of Anesthesiology, University of Kentucky, 800 Rose Street; N218, Lexington, Kentucky 40536-0293 USA. Phone: 606-323-5956; Fax: 606-323-1080; E-mail: psloan@uky.campus.mci.net 


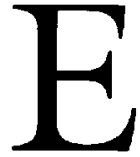

PIDURAL hematoma is a rare but devastating complication that may occur spontaneously or in association with neuraxial anesthesia. ${ }^{1}$ Risk factors include anticoagulant therapy (low molecular weight heparin, unfractionated heparin), coagulopathies and thrombocytopenia. The risk of epidural hematoma formation following epidural anesthesia is thought to be increased in patients with chronic renal failure. It is crucial that patients with epidural hematoma undergo emergency surgical decompression of the hematoma because this has been associated with improved neurologic outcome.

We report a case of epidural hematoma formation in a surgical patient with chronic renal failure who had an epidural catheter placed for postoperative analgesia.

\section{Case report}

A 58-yr-old woman $(60 \mathrm{~kg}, 165 \mathrm{~cm})$ was admitted for abdomino-perineal resection for adenocarcinoma of the rectum. She had a four year history of renal failure (CRF), long-standing Crohn's disease and deep venous thrombosis for which a caval filter had been placed. Pre-operative medication included methadone and prednisone. She did not take nonsteroidals, antiplatelet or anticoagulant medication. Previous surgery included small bowel resection for obstruction performed under general anesthesia. The patient and family had no history of bleeding disorders. On examination, no visible signs of coagulopathy were present. Blood pressure was $140 / 70 \mathrm{mmHg}$, heart rate of 100 bpm, temperature of $37.5^{\circ} \mathrm{C}$, and respiratory rate of 14. Laboratory values revealed a hematocrit of $26 \%$, platelets of 328,000 , PT of 11.3 , and PTT of 24.6. The patient underwent hemodialysis the night before surgery during which $4000 \mathrm{U}$ of heparin iv were administered.

In the operating room routine monitors (ECG, NIBP and pulse oximetry) were placed. After induction of general anesthesia, (thiopental, fentanyl, isoflurane, rocuronium, $\mathrm{O}_{2}$ ) the patient was turned to the lateral position and an epidural catheter easily threaded through an 18-gauge Tuohy needle at $\mathrm{L}_{1-2}$. There was a small amount of blood $(0.5 \mathrm{ml})$ aspirated through the catheter which cleared following irrigation. No further aspiration of blood was evident perioperatively.

The patient underwent total proctectomy and sigmoidectomy with colostomy, as well as total abdominal hysterectomy and partial vaginectomy. Surgery was uneventful, completed in the lithotomy position and lasted nine hours. During wound closure, the patient received $15 \mathrm{ml}$ epidural bupivacaine $0.25 \%$. The trachea was extubated in the operating room and she was transferred awake to the recovery room able to move both lower extremities. The patient received no postoperative heparin.

Postoperatively, the patient was started on an epidural infusion of bupivacaine $0.25 \%$ and 0.1 $\mathrm{mg} \cdot \mathrm{ml}^{-1}$ morphine sulfate at a basal rate of $2 \mathrm{ml} \cdot \mathrm{hr}^{-1}$ and an epidural PCA of $1 \mathrm{ml}$ every $10 \mathrm{~min}$ PRN. Routine post-operative laboratory work revealed: PT of 11.8 and PTT of 24.5. Neurological examination of both lower extremities twice daily was within normal limits for $48 \mathrm{hr}$.

The patient underwent hemodialysis on the third postoperative day (about $36 \mathrm{hr}$ after surgery), but no heparin was given. Ten hours later, the patient complained of severe lumbar back pain. Examination revealed motor weakness and sensory deficits in both lower extremities. The epidural infusion was stopped and MRI of the lumbar spine (Figure) revealed an epidural hematoma extending from $T_{12}$ to $L_{2}$ with spinal cord compression. Decompressive laminectomy evacuated an epidural hematoma and the patient eventually recovered moderate $(3 / 5$ lower extremity weakness) neurologic function. The patient died seven months later from systemic sepsis.

\section{Discussion}

Spinal hematoma is a rare but potentially catastrophic complication associated with neural blockade. A recent retrospect analysis of case reports estimates the incidence to be 1:190,000 after epidural anesthesia. ${ }^{2}$ Our case documents epidural hematoma formation with neurological compromise in a patient with chronic renal failure. The patient had no known coagulopathy or risk factors associated with epidural hematoma formation. Since post-operative hemodialysis was planned to be heparin-free, the most important risk factor for the development of epidural hematoma appears to be the coagulopathy of CRF. ${ }^{3}$ The exact onset of the epidural hematoma cannot be known, however the symptoms did not occur until the third post-operative day about $60 \mathrm{hr}$ after the epidural catheter placement. This suggests a late onset of epidural hematoma formation.

Risk factors (Table) for the development of the spinal hematoma include anticoagulant therapy, difficult or traumatic puncture, and thrombocytopenia. ${ }^{2}$

TABLE Patients at Risk for Spinal Hematoma

Known coagulopathy

Intravenous anticoagulant therapy

Thrombocytopenia

Difficult or traumatic needle/catheter insertion

Known spinal cord pathology

Perioperative low molecular weight heparin

Chronic renal failure 


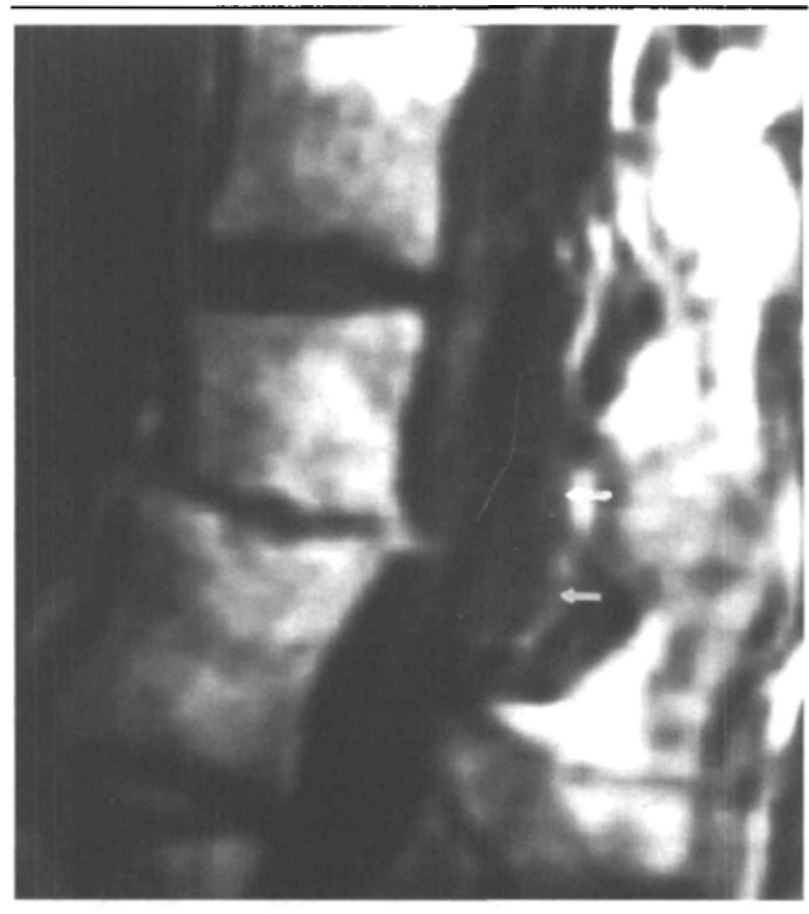

FIGURE Epidural hematoma collection (arrows) seen at $\mathrm{L}_{1^{-}{ }_{2}}$.

The risk of epidural hematoma during neuraxial blockade is increased in CRF, however the mechanism of action is incompletely understood. Regional techniques for patients with CRF have not resulted in a higher rate of hematoma complications. ${ }^{4}$ The coagulopathy of CRF is thought to be secondary to platelet dysfunction. ${ }^{5}$ Platelet counts are usually normal, although thrombocytopenia has been reported, and hemostasis improves with regular dialysis or erythropoietin therapy.

The use of heparin during dialysis of patients with CRF may be a risk factor since the half-life of heparin used during dialysis of renal failure patients may be increased. ${ }^{3}$ Nonetheless, surgery is usually started several hours post-dialysis, residual heparization may be reversed with protamine, and a preoperative PTT may provide some reassurance. In our patient, the epidural catheter was placed $12 \mathrm{hr}$ after heparin $(4,000 \mathrm{u})$ was given during hemodialysis. Assuming a half-life of heparin to two to four hours, sufficient time would have elapsed for coagulation to return to normal before epidural replacement. During post-operative hemodialysis, no heparin was used. The decision to perform neuraxial blockade on a patient receiving perioperative standard heparin or low molecular weight heparin must be made on an individual basis, weighing the risk of spinal hematoma with the benefits of regional anesthesia. Antiplatelet therapy given preoperatively does not increase the risk of spinal hematoma associated with regional anesthesia. ${ }^{6}$ Patients receiving low molecular weight heparin (LMWH) preoperatively should receive epidural needle placement a minimum of 10-12 hr following the last LMWH dose, and postoperative initiation of LMWH therapy should be delayed as long as possible: 12-24 hr. ${ }^{7}$

Patients at increased risk for spinal hematoma and receiving epidural analgesia should receive neurological evaluation at least every $12 \mathrm{hr}$. New symptoms of severe low back pain, and acute motor and sensory deficits in the lower extremities alerted the authors to the complication of epidural hematoma. The use of dilute local anesthetic solutions in combination with opioid spinal analgesics permitted immediate evaluation of the patients' neurologic status, which led to early diagnosis of the epidural hematoma.

We report the first case of epidural hematoma in a surgical patient with CRF and epidural postoperative analgesia. The only risk factor was a history of CRF. High-risk patients should be monitored closely postoperatively for early signs of cord compression. If spinal hematoma is suspected, MRI followed by decompressive laminectomy should be performed without delay.

\section{References}

1 Metzger G, Singbartl G. Spinal epidural hematoma following epidural anesthesia versus spontaneous spinal subdural hematoma. Two case reports. Acta Anaesthesiol Scand 1991; 35: 105-7.

2 Wulf $H$. Epidural anaesthesia and spinal haematoma. Can J Anaesth 1996; 12: 1260-71.

3 Cranshaw J, Holland D. Anaesthesia for patients with renal impairment. Br J Hosp Med 1996; 55: 171-5.

4 Linke CL, Merin RG. A regional anesthetic approach for renal transplantation. Anesth Analg 1976; 55: 69-73.

5 Aldrete JA, Daniel $W_{2}$ O'Higgins JW, Homatas J, Starzl $T E$. Analysis of anesthetic-related morbidity in human recipients of renal homografts. Anesth Analg 1971; 50: 321-9.

6 Horlocher TT, Wedel DJ, Schroeder DR, et al. Preoperative antiplatelet therapy does not increase the risk of spinal hematoma associated with regional ancsthesia. Anesth Analg 1995; 80: 303-9.

7 Horlocker TT, Heit JA. Low molecular weight heparin: biochemistry, pharmacology, perioperative prophylaxis regimens, and guidelines for regional anesthetic management. Anesth Analg 1997; 85: 874-85. 
8 Horlocker TT, Wedel DJ. Spinal and epidural blockade and perioperative low molecular weight heparin: smooth sailing on the Titanic (Editorial). Anesth Analg 1998; 86: 1153-6. 